\title{
A Aprendizagem e o Desenvolvimento do Surdo na Perspectiva Sociointeracionista de Lev Vigotsky
}

\author{
Alexsandra dos Santos Barbosa'; Bruno Pinto Freire ${ }^{2}$; Jarles Lopes de Medeiros ${ }^{3}$
}

Resumo: O presente estudo tem por objetivo discutir o conceito de surdez, com as características e particularidades que permeiam o desenvolvimento dos sujeitos em tal condição. A proposta é identificar ações para que o sujeito surdo ou a pessoa com ausência parcial da audição, possa ser incluída no processo de aprendizagem escolar e, de convivência social saudáveis ao seu pleno desenvolvimento. O educador, de uma maneira geral, tem um papel importante na compreensão e é grande a sua responsabilidade em promover a participação de todos no processo de construção do conhecimento.

Palavras-chave: Convivência social. Surdez. Vygotsky.

\section{The Learning and Development of the Deaf in the Socio-Interventionist Perspective of Lev Vigotsky}

\begin{abstract}
The present study aims to discuss the concept of deafness, with the characteristics and peculiarities that permeate the development of the subjects in such condition. The proposal is to identify actions for the deaf subject or the person with partial absence of hearing, can be included in the process of school learning and of social coexistence healthy to its full development. The educator, in a general way, has an important role in the understanding and he also has a great responsibility in promoting the participation of everyone in the process of knowledge

construction.
\end{abstract}

Keywords: Social coexistence. Deafness. Vygotsky.

\section{Lev Semenovith Vygotky e o Sóciointeracionismo}

De acordo com Santos, Oliveira e Junqueira (2014), Lev Vygotsky (1896-1934), bielorusso de família judia, cursou Direito na universidade de Moscou e, com apreço significativo

\footnotetext{
1 Mestranda em Filosofia no Curso de Mestrado Profissional do Programa de Pós-graduação da Universidade Federal do Ceará (PROFILO/UFC). Graduada em Filosofia pela Universidade Federal do Ceará (UFC).Professora de Filosofia na Secretaria da Educação Básica (SEDUC). E-mail: alexsandrabarbosademoraes@gmail.com

${ }^{2}$ Graduado em Psicologia pela Universidade de Fortaleza (UNIFOR). Especialista em Caráter e Residência Multiprofissional (UVA/ESFVS) e em Educação Inclusiva (UECE). Psicólogo do Programa de Proteção a Crianças e Adolescentes Ameaçados de Morte (PPCAAM/CE). Email: brunopfreire@ hotmail.com

${ }^{3}$ Doutorando em Educação no Programa de Pós-graduação em Educação Brasileira da Universidade Federal do Ceará (PPGE/UFC). Mestre em Educação (UFC). Especialista em Psicopedagogia Institucional e Clínica pela Faculdade da Aldeia de Carapicuíba (FALC). Graduado em Pedagogia pela Universidade Estadual do Ceará (UECE) e Licenciado em Língua Portuguesa pela Faculdade da Grande Fortaleza (FGF). Professor de Língua Portuguesa na SEDUC. E-mail: jarlles@ hotmail.com
} 
pelas artes e pela Psicologia, tornou-se um autêntico autodidata e escritor em ambas as áreas, também influenciando diretamente o campo da educação.

Vygotsky, continuam os autores, é compreendido como um pensador interacionista, construtivista e cognitivista. Interacionista por entender que o ser humano se desenvolve se torna um ser social a partir do convívio e do contato com o outro. Construtivista por acreditar que todo conhecimento é construído em relação, e não apenas passado de uma pessoa para outra. E, por fim, cognitivista por buscar estudar a origem, a gênese do conhecimento do homem.

Como ressalta Oliveira (2015), Vygotsky deu maior ênfase em seus estudos ao desenvolvimento do ser humano através do contato social, ressaltando o papel da cultura e da linguagem como axiomas do processo de socialização do indivíduo. Nesse sentido, a linguagem seria o principal mediador das relações, tornando-se peça-chave para a aprendizagem e a evolução.

Assim, compreende-se que o homem é um sujeito de possibilidades e potencialidades e, muitas destas, desdobrar-se-ão a partir do contato social, ou, ao contrário, poderão jamais emergir por ausência dos estímulos adequados. Santos, Oliveira e Junqueira (2014) trazem o papel do mediador como figura central na teoria de Vygotsky para o processo de construção do conhecimento, como destacam:

[...] o conhecimento estava na interação do meio como objeto de aprendizagem, refletindo sua compreensão, de que tanto as utilizações de recursos materiais ou psicológicos, como também a presença de agentes mediadores na figura do mais experiente, representam uma proposta pedagógica que parte do pressuposto de que o indivíduo constrói o conhecimento na sua interação com o meio, no entanto, essa relação é permeada por um contato com o outro, tendo aqui a clareza de que esse outro desempenhará um papel de extrema relevância no processo de aprendizagem (p. 17).

A mediação social tem um lugar central no processo de construção do conhecimento. $\mathrm{O}$ sujeito aqui não é mais solitário em sua aprendizagem, tornando-se o único responsável pelo seu "fracasso" quando não alcança uma expectativa escalonada e generalista. O meio social no qual este está inserido, com suas múltiplas influências, passa a representar aspectos fundamentais no desenvolvimento da aprendizagem de cada pessoa, ocorrendo, assim, uma reconstrução constante e compartilhada do conhecimento, gerando, de modo mais amplo, o desenvolvimento humano destacado por Vygotsky (SANTOS, OLIVEIRA e JUNQUIRA, 2014). 
Portanto, dentro do campo institucional da educação, Vygotsky afirmava que o trabalho com grupos heterogêneos, compostos por crianças de sexos e idades distintas, por sua variedade inerente, levava ao desenvolvimento com uma qualidade diferenciada e significativa, superando os aspectos formais do aprendizado, situando a criança no convívio social da alteridade. Nas palavras dos autores:

[...] uma abordagem da transmissão cultural, tanto quanto do desenvolvimento humano, que não "desabrocha" por si só, mas é gerado e impulsionado pela aprendizagem. A criança se desenvolve, constitui as capacidades, habilidades e aptidões humanas, porque aprende. [...] para Vygotsky a intervenção mediadora é fundamental (p.20).

Oliveira (2015) observa que, dentro de sua teoria sócio-histórica, Vygotsky estruturou metodologicamente o desenvolvimento do ser humano em quatro campos: o filogenético, o ontogenético, a sociogênese e a microgênese. O primeiro faz referência à evolução da espécie humana, ressaltando o surgimento do Homo sapiens a partir do momento em que pensamento e linguagem se tornam tão imbricados que permitem ao homem se organizar racionalmente em sociedade do modo bastante elaborado.

O segundo se volta para o desenvolvimento do homem, de seu nascimento à morte. Ressaltando a relação entre os processos orgânicos e sociais que apresentam influência direta da linguagem como mediador do crescimento humano.

Já na sociogênese, “[...] sua atenção recaiu sobre a influência que os indivíduos recebem a partir de seu convívio com o contexto sócio cultural" (OLIVEIRA, 2015, p. 56). Afirma que os processos psicológicos superiores (atenção, memória, linguagem, etc.) têm sua gênese na interação social. Por fim, na microgênese, lida com o desenvolvimento do indivíduo observando suas próprias experiências, vislumbrando os saltos qualitativos de lidar com o mundo à medida que cresce enquanto sujeito integral.

Dentro dessa perspectiva, torna-se importante refletir como um sujeito surdo, ou com perda parcial e significativa da audição, pode se tornar o homem social ressaltado por Vygotsky, visto que a linguagem pode se torna um empecilho dentro uma logística oralizada em que se constitui a nossa sociedade.

Vygotsky traz ainda o conceito de Zona Proximal de Desenvolvimento (ZPD), espaço de crescimento do sujeito que está entre os recursos já construídos pelo indivíduo e as possibilidades de aprendizagem que este pode alcançar, observando o fundamental papel de um 
mediador, ou como coloca Oliveira (2015), o mais experiente, como facilitador e colaborador na construção do conhecimento e, por consequência, do desenvolvimento do indivíduo.

\section{A Surdez}

Entende-se que cada sociedade tem um modo particular de apreender o mundo, o que gera valores, comportamentos comuns compartilhados e tradições culturais. Até a modernidade, os registros que se têm de sujeitos surdos, ou portadores de outras deficiências, referem-se ao descaso, sacrifícios e exclusões. Somente na Idade Média a Igreja passa a condenar o infanticídio, fornecendo causas sobrenaturais às "anormalidades" desses indivíduos (KANNER, 1964). O surdo, visto como ser irracional e castigado, não tinha o direito de ser educado e socializado, vivendo sozinho e na miséria.

Sacks (1989) aponta que, até então, não havia notícia de qualquer experiência educacional direcionada a esse público. Somente no século XVIII, na França, surgiu a primeira Instituição Escolar para crianças surdas, onde foi utilizada a Língua de Sinais a partir de uma combinação com o alfabeto francês. A escola Ábade Michel de L'epée, que carrega o nome de seu fundador, começou a mudar o percurso da história dessas pessoas.

No ano de 1857, o também professor Ernet Hwet, o qual era surdo e francês, veio ao Brasil a convite do Imperador D. Pedro II para trabalhar na educação de surdos. Funda-se o Instituto de Surdos-Mudos, o qual se desdobrou no atual Instituto Nacional de Educação de Surdos - I.N.E.S. Em 1864, o professor surdo francês Laurent Cler, seguidor de L'epée, fundou junto com Thomas Gallandet a primeira escola Estadunidense para surdos, que no mesmo ano passou a ser a única universidade para surdos no mundo (SACKS, 1989).

Cardoso e Capitão (2007) destacam que nos estudos sobre o desenvolvimento cognitivo do surdo, há três cortes epistêmicos claramente definidos no modo como a sociedade vê esse sujeito na contemporaneidade. Em 1923, as crianças surdas eram consideradas mentalmente inferiores às ouvintes, sob a justificativa de que a surdez também afetava o cérebro, causando retardo mental. Mais tarde, em 1953, passou-se a considerar que surdos e ouvintes possuíam desempenho intelectual similar, mas que os primeiros eram mais ligados ao pensamento concreto e tinham menos capacidades de raciocínio abstrato, dificultando a generalização do pensamento. Poucos anos depois, em 1960, afirmou-se que ambos os grupos eram iguais e que 
a ausência da fala não impediria o desenvolvimento intelectual do surdo, perspectiva que se firmou até a atualidade.

De um ponto de vista orgânico, a perca e a deficiência auditiva são sinônimas, observando-se apenas que o primeiro termo se refere a quem nasceu ouvinte e perdeu a audição com o tempo. A maioria dos casos de perca auditiva ocorre, geralmente, com pessoas idosas por conta de um desgaste dos folículos do ouvido interno. Isto pode ser corrigido com auxílio do aparelho auditivo, o qual eleva o volume do som, aumentando, assim, a vibração sentida pelo ouvido. Para perca auditiva, em raríssimos casos, é aconselhável a cirurgia de Implante Coclear (IC), aparelho que estimula o nervo auditivo através de pequenos eletrodos que são colocados dentro da cóclea (OLIVEIRA, 2005). Segundo o Decreto 5296/04 (BRASIL, 2004), é considerada deficiência auditiva: perda bilateral, parcial ou total de quarenta e um decibéis ou mais, aferida por audiograma nas frequências de $500 \mathrm{~Hz}, 1000 \mathrm{~Hz}, 2000 \mathrm{~Hz}$ e $3000 \mathrm{~Hz}$.

\section{O Nascimento e a Interação Social}

Desde as primeiras semanas de vida a família pode perceber se o recém-nascido tem alguma perca severa de audição. Se o bebe for exageradamente quieto, ou não apresentar movimentos na cabeça após um barulho forte, ou mesmo não se acalmar quando a mãe tentar niná-lo apenas com a voz. Quanto mais cedo for diagnosticada a surdez ou déficit auditivo parcial, melhor para o desenvolvimento da criança, pois mais adaptável ao seu funcionamento poderão ser os estímulos do meio social e dos mediadores da aprendizagem, na perspectiva de Vygotsky. No entanto, observa-se que “[...] com frequência a criança fica sem atendimento até o momento de ir à escola. Quanto mais tempo se passa, maiores são as dificuldades de desenvolvimento, tanto no campo da linguagem, quanto nos níveis sociais, psíquico, e cognitivo" (BRASIL, 2000).

A relação mãe-bebê é de total importância para o desenvolvimento do pensamento na criança, pois quando o bebê passa por determinada sensação e comunica, ao seu modo, a sua genitora, esta, geralmente, tenta ajudá-lo, esboçando reações com sons e gestos. Dentro dessa dinâmica relacional, o pequeno indivíduo começa a sentir e decodificar o mundo no qual está inserido, para posteriormente criar significados e conceitos para cada tipo de expressão. 
Quanto antes a lesão for detectada e as devidas providências tomadas, como, por exemplo, a maneira como vão usar da linguagem para criar seu filho (oral, sinais ou bilíngue), melhor poderá ser o desenvolvimento do sujeito. O problema é que, muitas vezes, demora-se a descobrir a ausência auditiva no bebê, pois o desenvolvimento de uma criança que nasce surda se processa normalmente, tal como na criança ouvinte, ficando as suspeitas de surdez adormecidas até que algum incidente possa comprová-la. Essa situação de espera pode acarretar em inúmeras consequências graves, mostrando-se de fundamental importância os testes para a verificação de uma audição normal.

Assim, muitas vezes, só por volta de um ano de idade é que as diferenças e dificuldades de comunicação são notadas, sendo esse intervalo de tempo entre os indicadores dos pais de algo errado e o próprio diagnóstico um período em que aumenta o sentimento de incerteza, criando ansiedade e angústia nos pais (COSTA, 2000). Todo esse processo é muito desgastante e atribulado para a família, o que pode trazer questões negativas que a acompanharão por muito tempo. Caso tais vivências não sejam ressignificadas, podem marcar um mal-estar intenso que despotencializará a todos os membros familiares, principalmente o surdo, fomentando um mito de surdez atrelado a deficiência e a incapacidade (REZENDE, KROM, YAMADA, 2003).

Levando-se em conta que $90 \%$ das crianças surdas são filhas de pais ouvintes (RODRIGUES e PIRES, 2002), a preocupação em como fazer essa relação ser a melhor possível deveria ser prioridade, o que muitas vezes de fato é o objetivo, porém com soluções malsucedidas. Assim, a família, enquanto sistema, muitas vezes não consegue sair potencializada desse contexto, por não lidar apropriadamente com a situação, acessando um caminho não saudável para manter o equilíbrio no grupo.

A interação social do surdo é diferente da que ocorre com a massa populacional, e para olhar com singularidade seu ambiente é preciso instrumentalizar-se, aprender outros canais de comunicação que não apenas o verbal, tampouco pensá-lo isolado do contexto que o permeia. Diante dessa percepção, podemos pensar o desenvolvimento do sujeito surdo a partir de seu meio familiar e educacional, no qual se utiliza, predominantemente, uma comunicação oral. Nessa perspectiva, Goldfeld (1997) coloca que:

[...] é a linguagem que permite o salto do sensorial nas pessoas, [...] onde a dificuldade dos surdos ocorre pelo fato de as línguas auditivas- orais serem as únicas utilizadas pela grande maioria das comunidades, e a surdez impossibilita a criança de adquiri-la espontaneamente. [...] Portanto, ressalta que os problemas da surdez são decorrentes das questões sócio- culturais e que a educação dessas crianças de ter como objetivo a minimização destes danos (p. 78). 
A esse modo, é fundamental questionar quais as consequências no desenvolvimento de sua vida que poderão ser positivas, ou não, procedendo desses ambientes, já que a família e a escola têm fundamentais colaborações em como essa pessoa irá se desenvolver e enfrentar as situações sociais experienciadas no futuro. Dessa forma, o Ministério da Educação - MEC (BRASIL, 2000) ressalta que:

\begin{abstract}
Para a criança surda o contato deve ser feito por meio de sinais espontâneos e expressões faciais cujo significado deve ser compreendido pelos pais e professores, que precisam valorizar tais manifestações como forma de comunicação e mostrar compreensão. Toda criança adquire a linguagem naturalmente, por meio da interação: fala é uma das manifestações da linguagem, tal como sinais, gestos, e a escrita são formas de estabelecer a comunicação e possibilitar a representação do pensamento.
\end{abstract}

Segundo Rodrigues e Pires (2002), é a dificuldade de comunicação que mais perturba o desenvolvimento de uma criança surda. Saber como as relações ocorrem, formando esse sujeito, desde os seus primeiros momentos da existência, requer enfoque na família e na sua relação para com esse ambiente. Os contatos iniciais desse filho com o mundo trarão dimensão fundamental para que se possa compreendê-lo melhor no decorrer de sua vida.

É possível sustentar a premissa de perdas psicológicas para com a surdez, mas estas não seriam inerentes diretamente a essa condição, e sim geradas por conflitos sociais, ocupacionais, pedagógicos e familiares (CARDOSO e CAPITÃO, 2007), ou seja, em micro-relações com a família e em macro-relações com a sociedade, e não simplesmente pelo fator orgânico de não poder ouvir.

A esse modo, tratar o comportamento do surdo isoladamente, separado-o do ambiente que o produziu, ou seja, trabalhar apenas com esse, deixando de fora o seu contexto familiar e escolar de desenvolvimento, seria superficial e limitado, visto que, como ressalta Vygotsky (apud OLIVEIRA, 2015), é nas interações e retroalimentações sociais que se constitui e se percebe o humano.

A partir dessa visão, abre-se a possibilidade de um desenvolvimento sem adoecimento inerente como possível para qualquer pessoa, pois o padecer está no sistema e no indivíduo isolado concomitantemente, sendo preciso que ambos sejam tratados numa perspectiva dialógica. 


\section{A Inclusão da Pessoa Surda na Perspectiva de Vygotsky}

Observa-se a existência de um imbróglio acerca do que é o Construtivismo enquanto prática pedagógica, entendendo tal fato por se tratar de uma mudança paradigmática na Educação Formal e Institucional, visto estimularem alterações nos modos de pensar e agir das pessoas. Como expõem Santos, Oliveira e Junqueira (2014), essas teorias trazem a ideia vygotskyniana "[...] de que o conhecimento é ativamente construído pelo aluno e não apenas transmitido pelo professor e passivamente apreendido" (p.7). Tal perspectiva é bem antagônica ao formato bancário de educação que o sistema brasileiro escolar segue de forma generalizada, utilizando os termos de Freire (2005). Portanto, nas últimas décadas e, principalmente, no século XXI, os conceitos construtivistas têm se disseminando e incorporado às propostas de funcionamento escolares.

A partir das informações coletadas e discutidas, entrelaçadas às experiências profissionais em instituições escolares dos autores deste artigo, compreende-se que Vygotsky (1984) tem fundamental importância na realidade educacional e social do Brasil e do Ceará, pois busca enfatizar as particularidades dos contextos sociais como aspectos importantes para o desenvolvimento da aprendizagem, rechaçando formatos generalistas e bancários de ensino que se sobrepõem à individualidade dos indivíduos.

Portanto, as ideias de Vygotsky, assim como de Santos, Oliveira e Junqueira (2014), estimulam a transformação da sociedade ao afirmar que todo ser humano é passível de construção do conhecimento e que cada um não poderá se desenvolver sem o contato com o outro, gerando práticas mais humanas e valorativas das diferenças existenciais imbricadas em cada sujeito. Nesse sentido, trabalhar com o surdo solicita, primeiramente, que haja uma linguagem comum como viés de compreensão do outro e das informações trocadas. A partir do momento que o educador conseguir uma comunicação com o educando surdo, poderá conhecêlo e entendê-lo em sua singularidade, com dificuldades e potencialidades inerentes a sua existência.

Como ressalta Oliveira (2015), fazendo referência às ideias de Vygotsky, é necessário a autopercepção de como se age para com essas pessoas, a partir de uma leitura crítica, histórica e cultural. Pensar o surdo na perspectiva da alteridade, com o conceito de diferença ao invés de deficiência é primordial (PERLIN, 1998), bem como procurar compreender como ocorre o seu desenvolvimento. É preciso concebê-lo integralmente, em diferentes âmbitos da vida enquanto 
criança, mais no ceio da família, e, posteriormente, no adentrar da vida escolar, momento este que trará uma nova perspectiva experiencial e acarretará em mudanças em suas relações familiares e sociais.

A comunidade surda tem uma unidade muito forte. Porém, é importante que a pessoa surda possa ser incluída em toda a sociedade, em um processo muito além da sala de aula. Algo que poderia reforçar esse processo, principalmente para o adolescente, é o ensino da Língua Brasileira de Sinais (LIBRAS), pelo menos, no primeiro ano do Ensino Médio. Provavelmente, veríamos mais jovens surdos em escolas regulares, possibilitando a maior interação entre eles, relações que trariam variabilidade e enriquecimento de experiências para todos os envolvidos.

Atividades com estímulos variados, tais como recursos audiovisuais, táteis, olfativos e gustativos podem fazer a diferença na compreensão dos conteúdos e na interação entre os participantes, sejam estes ouvintes ou não. Respeitando as características de desenvolvimento e maturação de cada turma e as particularidades de seus integrantes, torna-se fundamental que toda proposta de atuação esteja balizada pela comunicação, a qual irá elucidar e direcionar muitos aspectos da aprendizagem da turma. O professor é, sem dúvidas, um dos principais responsáveis.

Ressalta-se, também, o uso das chamadas metodologias ativas, as quais fomentam a participação criativa dos participantes, ou seja, educador e educandos envolvidos na construção do conhecimento, desde o planejamento até a execução. Outra possibilidade de trabalhar a inclusão de surdos em salas regulares são os formatos de linguagens universais, como o uso das variadas artes durante a abordagem dos conteúdos, tais como pintura, cinema (filmes do cinema mudo) fotografia, oficinas de sensações, manuseios e estudos com horta e farmácia viva, bem como esportes.

Assim, observa-se a importância de conhecer o grupo que é facilitado pelo educador, procurando sempre recursos comunicacionais que busquem atender às necessidades dos estudantes, assim como estimular a interação de forma transversal.

\section{Conclusões}

O presente trabalho se desenvolveu a partir de direcionamentos pedagógicos no Curso de Especialização em Educação Inclusiva no Centro de Educação (CED) da Universidade 
Estadual do Ceará (UECE), originando-se na disciplina Desenvolvimento Psicológico e Educação. Portanto, esse escrito se caracteriza como de cunho teórico, interdisciplinar e reflexivo (MINAYO, 2010), no qual se buscou suscitar e dialogar com possibilidades didáticopedagógicas de atuação junto a pessoas surdas, tendo como bases os conceitos de Vygotsky (1984), dentre outros autores.

O estudo não esgota as possibilidades de discussão acerca da temática. Pesquisas ainda devem ser realizadas para que se possa reconhecer o surdo em sua singularidade dentro de nossa sociedade e cultura, sendo importante que esse processo de esclarecimento ocorra nos mais variados âmbitos de convivência do ser humano, como família e/ou escola, dentre outros espaços sociais.

Abrir novos campos de percepção para olhar esse indivíduo, compartilhar suas formas de viver entendendo melhor suas particularidades, colocar-nos-á diante da possibilidade de contribuir para o pleno desenvolvimento humano. O educador, de modo geral, tem papel primordial no entendimento dessas existências, sendo sua responsabilidade procurar compreender e auxiliar na forma como se organizam e vivenciam, para que a convivência possa ser permeada pela inclusão.

\section{Referências}

BRASIL. Ministério da Educação (MEC). Deficiência auditiva. Caderno da TV escola, 2000. Decreto $N^{\circ} 5.296$ de 2 de Dezembro de 2004.

CARDOSO, L. M., CAPITÃO, C. G. Avaliação psicológica de crianças surdas pelo Teste das Pirâmides Coloridas de Pfister. PsicoUSF, dez. 2007, vol. 12, nº 2, p. 135-144.

COSTA, A. V. Atitudes dos pais de adolescentes surdos face à integração socio-afectiva dos seus filhos. Lisboa: Instituto Superior de Psicologia Aplicada. Monografia de Licenciatura em Psicologia Clínica, 2000.

FREIRE, Paulo. Pedagogia do Oprimido. Rio de Janeiro: Paz e Terra, 2005.

GOLDFELD, M. A criança surda: linguagem e cognição numa perspectiva sóciointeracionista. São Paulo: Plexus, 1997.

KANNER, Léo. A history of the care and study of the mentally retarded. Springfield, Illinois: Charles C. Thomas Publisher. 1964. 
MINAYO, M. C. S. O desafio do conhecimento: pesquisa qualitativa em saúde. 12. Ed - São Paulo: Hucitec, 2010.

OLIVEIRA, José Antonio A. de. Implante Coclear. Simpósio Surdez: implicações clínicas e possibilidades terapêuticas. Medina, Ribeirão Preto, 38 (3/4): 262-272, jul/dez. 2005.

OLIVEIRA, J. C. R. Desenvolvimento psicológico: as contribuições de Piaget e Vigotsky para pessoas com necessidades educativas especiais. In SANTOS, G. C. S., RIBEIRO, R. R. R. P. C., SAMPAIO, R. M. G., PINTO, S. E. L. (Orgs.). Inclusão: saberes, reflexões e possibilidades de uma prática em construção. Fortaleza: EdUECE, 2015.

PERLIN, G. T. T. Identidades surdas. Porto Alegre: Mediação, 1998.

REZENDE, I. G., KROM, M., YAMADA, M. O. A repetição integeracional e o significado atual da deficiência auditiva. Psicologia: Teoria e Pesquisa, Brasília, mai-ago. 2003, vol. 19, no2, p. 177-184.

RODRIGUES, A. F., PIRES, A. Surdez infantil e comportamento parental. Análise Psicológica, jul. 2002, vol. 20, n 3, p. 389-400.

SACKS, O. Vendo vozes: uma jornada pelo mundo dos surdos. Rio Janeiro: Imago,1989.

SANTOS, A. O., OLIVEIRA, G. S., JUNQUEIRA, A. M. R. Relações entre aprendizagem e desenvolvimento em Piaget e Vygotsky: o construtivismo em questão. Itinerarius Reflectionis - UFG, Jataí, julho-dezembro 2014, vol. 10, Nº 2.

VYGOTSKY, Lev S. A formação social da mente. São Paulo: Martins Fontes, 1984.

Como citar este artigo (Formato ABNT):

BARBOSA, Alexsandra dos Santos; FREIRE, Bruno Pinto; MEDEIROS, Jarles Lopes de. A Aprendizagem e o Desenvolvimento do Surdo na Perspectiva Sociointeracionista de Lev Vigotsky. Id on Line Rev.Mult. Psic., 2018, vol.12, n.40, p.614-628-638. ISSN: 1981-1179.

Recebido: $13 / 04 / 2018$

Aceito: 26/04/2018 